\title{
Anatomical Risk Factors for Rupture of the Anterior Cruciate Ligament: Magnetic Resonance Imaging Based Knee Joint Assessment
}

\section{Odile Fernande Zeh"1,2,3*, Mathurin Neossi Guena4, Michèle Pétronille Ndem Nyamfoum ${ }^{1,5}$, Julienne Onguene Medza1,2, Derek Dangoh Ndangoh1, Claude Sandra Raïssa Abomo Ngodo1, Maxwell Goudjou Sandjong1, Joseph Gonsu Fotsin ${ }^{1,2}$}

\author{
${ }^{1}$ Faculty of Medicine and Biomedical Sciences, University of Yaounde I, Yaounde, Cameroon \\ ${ }^{2}$ Yaounde Gynaecology Obstetrics and Pediatrics Hospital, Yaounde, Cameroon \\ ${ }^{3}$ Jordan Medical Centre, Yaounde, Cameroon \\ ${ }^{4}$ Biomedical Sciences Department, Faculty of Sciences, University of Ngaoundere, Yaounde, Cameroon \\ ${ }^{5}$ General Henri Mondor of Aurillac Hospital Centre, Aurillac, France \\ Email: *of_zeh@yahoo.fr
}

\begin{abstract}
How to cite this paper: Zeh, O.F., Neossi Guena, M., Ndem Nyamfoum, M.P., Onguene Medza, J., Ndangoh, D.D., Abomo Ngodo, C.S.R., Goudjou Sandjong, M. and Gonsu Fotsin, J. (2017) Anatomical Risk Factors for Rupture of the Anterior Cruciate Ligament: Magnetic Resonance Imaging Based Knee Joint Assessment. Open Journal of Radiology, 7, 228-240. https://doi.org/10.4236/ojrad.2017.74025
\end{abstract}

Received: October 9, 2017

Accepted: December 1, 2017

Published: December 4, 2017

Copyright (c) 2017 by authors and Scientific Research Publishing Inc. This work is licensed under the Creative Commons Attribution International License (CC BY 4.0).

http://creativecommons.org/licenses/by/4.0/

\section{Open Access}

\begin{abstract}
Anterior cruciate ligament (ACL) rupture is one of the most frequently encountered traumatic ligamentous lesions of the knee. Several intrinsic and extrinsic factors are linked to this lesion. Anatomical factors increase the anterior translation of the knee and thus promote the stretching and rupture of the anterior cruciate ligament. Objectives: To determine the anatomical risk factors favouring ACL rupture by comparing morphometric parameters of patients with knee ACL rupture to patients without ACL rupture, as well as the intercondylar notch index and the tibial slopes of the two groups and describing the ruptured ACLs and associated signs. Materials and Methods: We conducted a case-control descriptive analytical study in imaging centres of the General Henri Mondor of Aurillac Hospital Centre in France (CHM) and the Jordan Medical Centre of Yaoundé in Cameroon (CMJ). MRI exam protocols included T1 SE, T2 SE, proton density and Fat Sat sequences, with slices in all three planes. Morphometry knee variables measured in our study were: intercondylar notch index and the tibial slopes. These measurements were obtained from images stored in DICOM format and post processing software OsiriX MD ${ }^{\circledR}$ for CMJ patients and Explore ${ }^{\circledR}$ for CHM patients. Results: The study included 92 individuals, 38 in the case group and 54 in the control group. The mean age was 36.6 years for both groups; 35.5 years for the cases and 37.4 years for the controls. The sex ratio was 1.87 men for 1 woman in
\end{abstract}


both groups; 2.16 men for 1 woman for the case group. 53\% of ACL ruptures are partial, with the predominant direct sign being morphologic and signal abnormalities of the ACL. The most significant indirect sign of ACL rupture was mirror-image bone contusion that was observed in $47.3 \%$ of cases. In the case group, the mean lateral tibial slope was $4.003^{\circ}$, whereas it was $2.92^{\circ}$ in the control group. The comparison of means was estimated at approximately 0.039 ( $\mathrm{p}<0.05$ ), corresponding to a statistically significant difference. The means of the intercondylar notch indices were: 0.28 for the case group and 0.26 for the control group. The means of the median slopes were 4.93 for the case group and 4.90 for the control group. Conclusion: The increase in the lateral tibial slope was a risk factor for anterior cruciate ligament rupture in our study population. Intercondylar notch index and medial tibial slope did not show any statistical significant difference.

\section{Keywords}

Anatomical Factors, Anterior Cruciate Ligament Rupture, MRI of the Knee

\section{Introduction}

Anterior cruciate ligament rupture is one of the most frequently encountered traumatic ligamentous lesions of the knee. In France, there are 15,000 ACL ruptures per year during skiing [1]. Little is known of its prevalence in sub-Saharan Africa. It was estimated at $45.8 \%$ of the traumatic lesions of the knee according to a study published by Tapouh et al. in Cameroon in 2015 [2].

Anterior cruciate ligament (ACL) rupture is a severe knee injury, leading to functional instability in the short term and to early degenerative joint disease in the long term [3]. The diagnosis of ACL rupture has been improved through the use of magnetic resonance imaging (MRI), which is the best non-invasive modality.

Several risk factors have been proposed, both internal (anatomical, hormonal, neuromuscular, and familial) and external (type of sports, footwear, and environment) [1]. Studies on anatomical risk factors have been conducted, based on the anatomical femoral-tibial alignment, the size of the intercondylar notch or its index, the medial and lateral tibial slopes and the depth of the medial tibial plateau. These factors increase the anterior translation of the knee and thus promote stretching and rupture of the anterior cruciate ligament [1].

In our milieu, there is very little epidemiological data concerning lesions of the anterior cruciate ligament and their various risk factors whereas the risk is increasingly higher with the growing practice of sports, which are the greatest external risk factor of these lesions.

Our study aims to evaluate the intercondylar notch index and the tibial slopes as anatomical risk factors of rupture of the anterior cruciate ligament using MRI of the knee. 


\section{Materials and Methods}

\subsection{Study Population and Sampling}

The study population consisted of individuals in whom MRI of the knee was indicated for trauma in both study sites. The case group was composed of subjects with ACL rupture and the control group, those without ACL rupture, irrespective of age and sex.

Patients with known instability of the lower limbs, pathology related to ligamentous laxity, bone tumour or anterior knee surgery were excluded from the study.

\subsection{Data Collection Procedure}

The clinical information was obtained from medical reports. For the case group, both direct signs (ACL not seen, discontinuity, abnormal path and/or LCA signal abnormality) and associated with indirect lesions (bone contusions of the plateau Lateral tibial and medial condyle, meniscal fissure, anterior subluxation of the tibia on the femur, lesion of collateral ligaments, fracture of Segond) that led to the diagnosis of ACL rupture were determined.

For the control group, all MRI lesions of the knee were recorded.

\subsection{MRI Protocols and Measurement of Variables}

MRI scans were performed using the following MRI machines: HITACHI 0.5 Tesla for CMJ; SIEMENS 1.5 Tesla for CHM.

The MRI sequences used were T1 SE, T2 SE, proton density and Fat Sat. Slices in the three planes were used for interpretation of ACL rupture and for morphometry.

MRI images of the CMJ were stored in DICOM format and then analysed using the Osirix ${ }^{\circledR}$ post-processing software. The images CHM were analysed using the Explore ${ }^{\circledR}$ post-processing software.

\section{Morphometric parameters}

- Intercondylar notch index: We used the axial slice passing through the intercondylar notch, at the widest part of the distal femoral epiphysis. The notch index was calculated by making the ratio between the width of the intercondylar notch and the width of the distal epiphysis of the femur measured on two strictly parallel lines (Image 1).

- Tibial slopes: These were measured using the new combined method proposed by Khan et al. [4], which had the smallest inter and intra-observer variabilities. From sagittal slices on the medial tibial sagittal section, we determined the axis of the tibia. This axis connects the centres of two circles, the first of which is tangent to the internal cortex of the proximal tibial epiphysis and the second, tangent to the cortex of the proximal diaphysis. The line perpendicular to the tibial axis was used as a reference. We then performed a superposition of the reference line on the sagittal slices passing through the centre of the lateral and medial tibial plateaus. The tibial slope 
corresponds to the angle formed between the reference line and the line tangent to the corresponding tibial slope (Images 2-4).

\subsection{Statistical Analyses}

Digital information was recorded and analysed using the software SPSS.24. Differences were considered statistically significant for p-values $<0.05$. The results were presented in tables and figures developed by SPSS.24 and Microsoft Excel 2016.

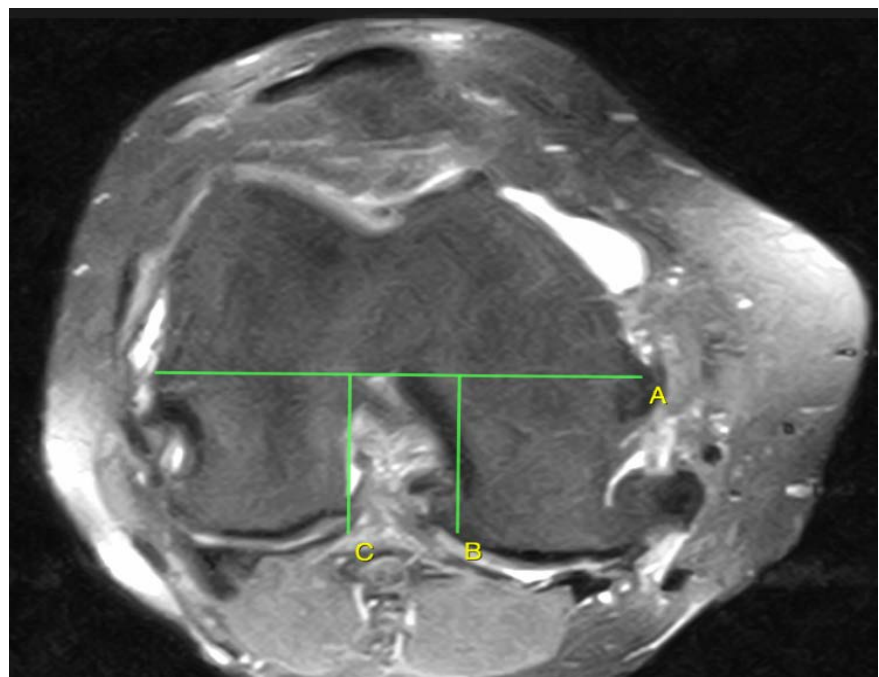

Image 1. MRI of the knee, T2 weighted axial slice through the intercondylar notch, showing the measurements of the width of the distal femoral epiphysis and the width of the intercondylar notch. Scale size: $5 \mathrm{~cm}$.

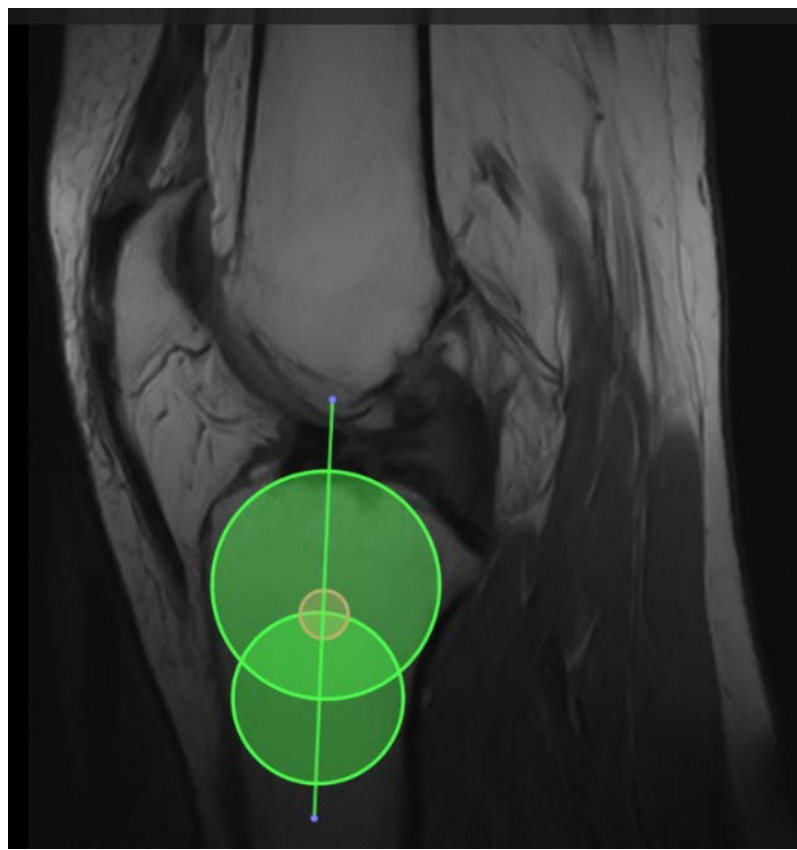

Image 2. MRI of the knee, T1 weighted mid sagittal slice, showing the measurement of the proximal tibial axis using the combined method. Scale size: $5 \mathrm{~cm}$. 


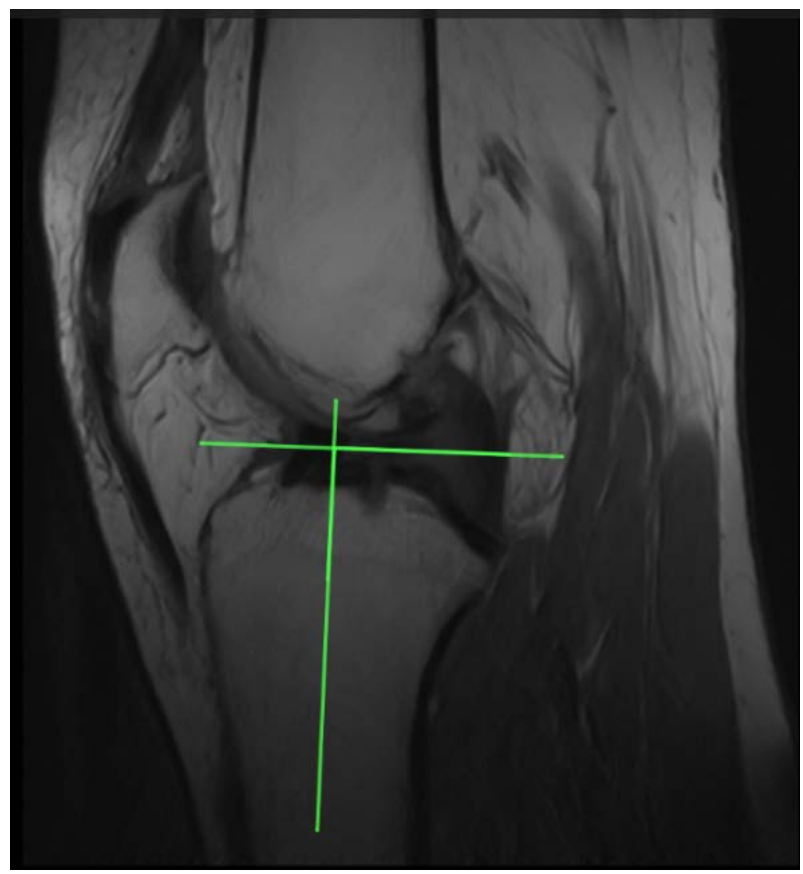

Image 3. MRI of the knee, T1 weighted mid sagittal slice, showing the proximal tibial axis and the reference line (perpendicular to the tibial axis) Scale size: $5 \mathrm{~cm}$.

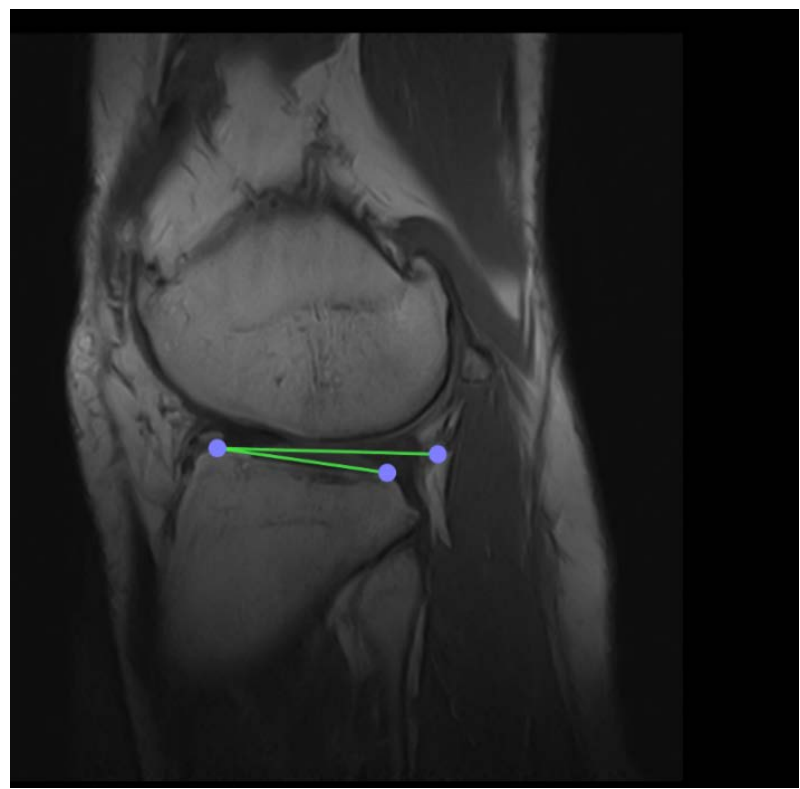

Image 4. MRI of the knee, T1 weighted sagittal slice through the midpoint of the lateral tibial plateau, showing the lateral tibial slope Scale size: $5 \mathrm{~cm}$.

\subsection{Ethical Considerations}

The study was carried out after obtaining an authorization from the Ethics Committee of the Faculty of Medicine and Biomedical Sciences of the University of Yaoundé I and the authorizations from the unit heads of both centres.

The anonymity of the participants included in the study was respected, as well as the confidentiality of the files consulted in the archives of these health struc- 
tures.

\section{Results}

\subsection{Study Population}

A total of 92 patients were enrolled in the study in the two groups; 38 patients in the case group with 18 selected at the CMJ and 20 at the CHM. 54 patients with MRI of the knee, without ACL rupture, constituted the control group.

\subsection{Demographic Characteristics}

The mean age of the entire study population was 36.66 years, with a mean age of 35.5 years in the case group and 37.48 years in the control group. The most represented age group was 20 - 29 years for the case group and 50 - 59 years for the control group (Table 1 ).

$65 \%$ of the population were males. The sex ratio was 1.87 men for 1 woman in the entire study population, 2.16 men for 1 woman in the case group and 1.7 men for 1 woman in the control group (Table 2).

The most represented age groups were 20 - 29 years for the case group and 50 - 59 years for the control group (Table 1).

We found a male predominance in both groups, with $68.4 \%$ of men in the case group and $63 \%$ in the control group (Table 2 ).

\subsection{MRI Findings of Patients in the Case Group}

Partial ruptures of the ACL of the knee are more frequent than the full-thickness

Table 1. Distribution of population with respect to age.

\begin{tabular}{ccccc}
\hline \multirow{2}{*}{ Age group (years) } & \multicolumn{3}{c}{ Case } & \multicolumn{2}{c}{ control } \\
\cline { 2 - 5 } & Frequency & Percent (\%) & Frequency & Percent (\%) \\
\hline $0-9$ & 1 & 2.6 & 1 & 1.9 \\
$10-19$ & 2 & 5.3 & 7 & 13.0 \\
$20-29$ & 13 & 34.2 & 13 & 24.1 \\
$30-39$ & 10 & 26.3 & 8 & 14.8 \\
$40-49$ & 6 & 15.8 & 8 & 14.8 \\
$50-59$ & 3 & 7.9 & 14 & 25.9 \\
$60-69$ & 3 & 7.9 & 3 & 5.6 \\
Total & 38 & 100.0 & 54 & 100.0
\end{tabular}

Table 2. Distribution of population with respect to gender.

\begin{tabular}{ccccc}
\hline \multirow{2}{*}{ Gender } & \multicolumn{2}{c}{ Case } & \multicolumn{2}{c}{ Control } \\
\cline { 2 - 5 } & Frequency & Percent (\%) & Frequency & Percent (\%) \\
\hline Masculine & 26 & 68.4 & 34 & 63.0 \\
Feminine & 12 & 31.6 & 20 & 37.0 \\
Total & 38 & 100.0 & 54 & 100.0 \\
\hline
\end{tabular}


ACL Ruptures

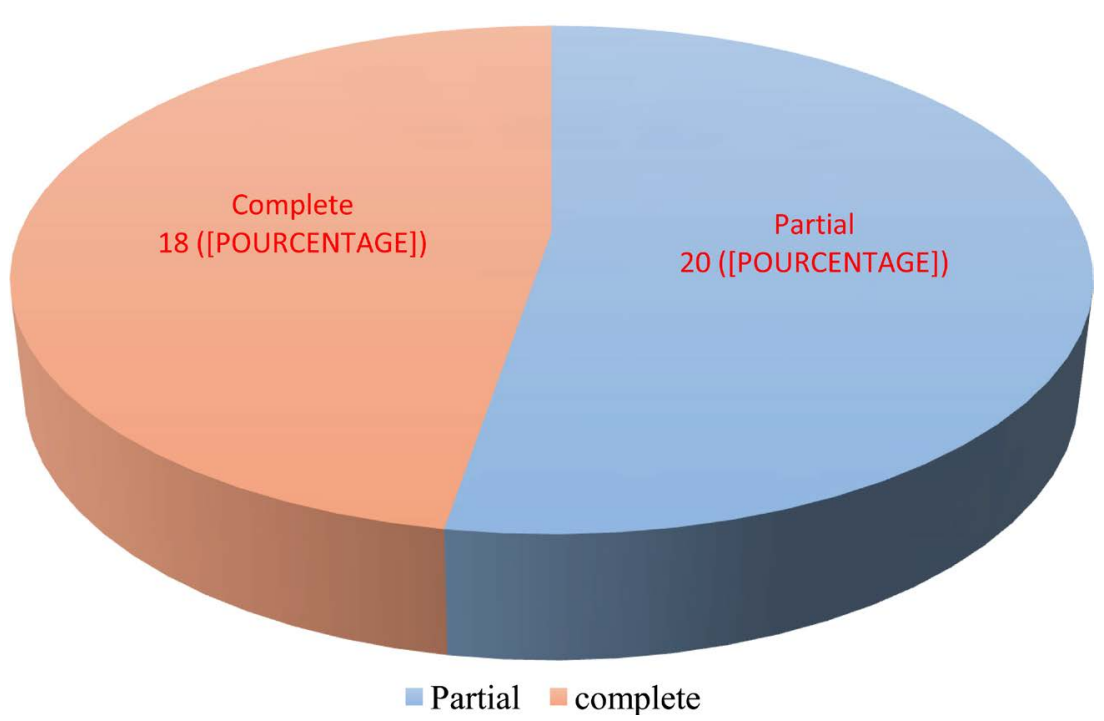

Figure 1. Types of ACL rupture.

Table 3. Direct MRI signs of ACL rupture.

\begin{tabular}{ccc}
\hline & Frequency & Percent (\%) \\
\hline Non visualised & 7 & 18.4 \\
Discontinuous & 6 & 15.7 \\
Abnormal course & 14 & 36.8 \\
Anomaly of morphology and signal & 23 & 60.5 \\
\hline
\end{tabular}

Table 4. Indirect MRI signs of ACL rupture.

\begin{tabular}{ccc}
\hline & Frequency & Percent (\%) \\
\hline Mirror-image bone contusions (lateral tibial and medial femoral) & 18 & 47.3 \\
Lateral meniscal lesion & 4 & 10.5 \\
Medial collateral ligament lesion & 6 & 15.8 \\
Femoro-tibial Subluxation & 3 & 7.9 \\
No sign & 13 & 34.2 \\
\hline
\end{tabular}

ruptures in sample (Figure 1).

Morphological and signal abnormalities of the ruptured ACL was the most direct sign of rupture found in our study (Table 3 ).

Indirect signs of ACL rupture can help to orientate and confirm the diagnosis in the existence of a doubt. In our study, bone contusions of the lateral tibial and medial femoral compartments were the most frequent, found in $47.3 \%$ of cases (Table 4).

In $71 \%$ of cases, intra-articular effusion was found in the case group. Lesions of the medial meniscus were also frequent in $34.2 \%$ (Table 5). 
Table 5. Signs associated with ACL rupture.

\begin{tabular}{ccc}
\hline & Frequency & Percent (\%) \\
\hline None & 4 & 10.5 \\
Materal meniscal lesion & 13 & 34.2 \\
Patellar extensor lesion & 5 & 13.1 \\
Other bone contusions & 3 & 5.3 \\
Intra-articular effusion & 7 & 7.9 \\
Articular cyst & 27 & 71 \\
Posterior cruciate ligament lesion & 1 & 2.6 \\
\hline
\end{tabular}

Table 6. Means and intervals of the intercondylar notch index and tibial slopes.

\begin{tabular}{ccccccc}
\hline & $\mathrm{N}$ & Minimum & Maximum & Mean & Standard deviation & Variance \\
\hline Index & 92 & 0.20 & 0.36 & 0.2693 & 0.03761 & 0.001 \\
Medial slope ( $\left(^{\circ}\right)$ & 92 & -3.5 & 9.9 & 4.517 & 1.8276 & 3.340 \\
Lateral slope $\left(^{\circ}\right)$ & 92 & -6.2 & 7.6 & 3.368 & 2.4882 & 6.191 \\
\hline
\end{tabular}

Table 7. Means of the intercondylar notch indices and of the tibial slopes in the case and control groups.

\begin{tabular}{ccccccc}
\hline & \multicolumn{3}{c}{ Case } & \multicolumn{3}{c}{ Control } \\
\hline & $\mathrm{N}$ & Mean & Std dev & $\mathrm{N}$ & Mean & Std dev \\
\hline Index & 38 & 0.2805 & 0.03698 & 54 & 0.2615 & 0.03636 \\
Medial slope $\left(^{\circ}\right)$ & 38 & 4.430 & 2.2645 & 54 & 4.600 & 1.6406 \\
Lateral slope $\left(^{\circ}\right)$ & 38 & 4.003 & 3.1902 & 54 & 2.920 & 1.7413 \\
\hline
\end{tabular}

\subsection{Analysis of Knee Morphometry}

The means of the parameters of the knee morphometry were $0.2693 ; 4.517$ and 3.368 respectively for the intercondylar notch index, the medial slope and the lateral slope (Table 6).

The lateral tibial slope was higher in the case group than in the control group. The medial tibial slopes and the intercondylar notch indices did not differ significantly between the two groups (Table 7).

Comparison of tibial slope means between the case and control groups was estimated at a p-value of 0.039 (Table 7), which corresponded to a statistically significant difference $(\mathrm{p}<0.05)$.

There was no significant difference between men and women in the same case and control groups with regard to the morphometric parameters studied (Table 8).

\section{Discussion}

\subsection{Materials and Methods}

Health-based risk studies are conducted using cohort or case-control studies. 
Table 8. Means of tibial slopes and intercondylar notch index of case and control groups, by sex.

\begin{tabular}{ccccc}
\hline & \multicolumn{2}{c}{ Case } & \multicolumn{2}{c}{ Control } \\
\cline { 2 - 5 } & Male & Female & Male & Female \\
\hline Index & 0.28 & 0.29 & 0.26 & 0.27 \\
Medial slope $\left(^{\circ}\right)$ & 4.4 & 4.6 & 4.5 & 4.7 \\
Lateral slope $\left(^{\circ}\right)$ & 4.1 & 3.8 & 2.8 & 3.2 \\
\hline
\end{tabular}

Our study was a case-control study. Similar studies designs have been carried out in the past by Simon et al. [4], Wordeman et al. [5] in the United States of America; Freychet et al. [6] in France, among many others. One of the most important sources of bias in a study of this type arises from the selection of the different subjects to constitute the case and control groups.

The CMJ is one of the centres in Cameroon carrying out MRI of the knee and receiving patients of diverse origins and pathologies. However, owing to the relatively recent functioning of this MRI service, justifying the limited number of its patients; this explains why we had just 18 patients with ACL ruptures, and fulfilling our selection criteria. It seemed wise to select all subjects with ACL ruptures in this health facility and meeting the inclusion criteria without distinction.

The Henri Mondor Hospital Center has an older MRI service and a better attendance. We conducted a random selection in order to reduce bias. This study was conducted retrospectively and prospectively.

The lack of some interesting clinical data such as medical and orthopaedic past histories, increased the risk of error with respect to other clinical factors.

The anatomical factors we choose to study were the notch index and the tibial slopes, which are the factors that are most widely used in recent publications.

The tibial slopes were measured using the new combined method which has the lowest inter and intra-observer differences. This is the method described and used by Khan et al. It combines the methods of Hudek et al. and Hashemi et al, specifying the selections of mid-sagittal slices for the determination of the tibial axis and the mid points of the tibial plateau for the measurements of angles [1].

\subsection{Demographic Data}

$65 \%$ of the study population were males, with a higher ratio in the case group than in the control group. Apart from gender-balanced studies of SonneryCottet et al. [7] in France and Helen C. Smith et al. [8] in USA who have a majority of female, the male is more represented in most studies. Tapouh et al. [2] in Cameroon, found $70.8 \%$ males with a sex ratio of 2.43 in a population with knee trauma, Tomas Fernandez-Jaen et al. [9] in Spain found 224 men and 84 Women in a population with ACL ruptures, Freychet et al. [6] in France found 33 boys and 16 girls in paediatric population.

This predominance of male gender in population is quite consistent with most 
publications in the literature, especially explained by the greater involvement of males in sporting and other physical activities.

The mean age was 36.6 years in the study population, with a mean of 37.48 years in the control group and 35.5 years in the case group. Tapouh et al. [2] who found a mean age of 35.36 years in Cameroonian population found similar results. A mean age of 33.8 years was found by Tomas Fernandez-Jae et al. [9] in a study population with ACL rupture in Spain.

\subsection{ACL Rupture}

In $53 \%$ of cases, the ACL rupture was a partial rupture. This is contrary to the result obtained by Tapouh et al, who found a predominance of full-thickness rupture (81\%) [2]. Partial ruptures represented $10 \%-35 \%$ of lesions according to Donell ST et al. [10]. The precise distinction between partial and full-thickness ruptures can be difficult and requires confirmation by complementary techniques, this could explain the statistical differences.

Among the signs associated with ACL ruptures we distinguished indirect signs which are those associated with a strong presumption of rupture of the ACL. The most prominent of the indirect signs was bone contusion of the lateral tibial and medial femoral compartments, estimated at $47 \%$ meanwhile $30 \%$ was obtained by Tapouh et al. In 34\% of the cases, no indirect signs were found. Intraarticular knee effusion was the most common associated sign, with $71 \%$ of cases in patients with ACL ruptures. Tapouh et al. found $51.4 \%$.

Lesions of the medial meniscus were the most frequent meniscal lesions ( $34.2 \%$ versus $10.5 \%$ for the lateral meniscus). This result is similar to that obtained by Lerais et al. and Tapouh et al., who found predominance of medial meniscal lesions at $23 \%$ and $22 \%$, respectively. This is contrary to the description made by Guenoun et al. in France, who found a predominance of the lateral meniscal lesions [11]. Meniscal involvement is related to the mechanism of trauma, which may explain the differences that can be found from one population to another depending on whether a VALFE or VARFI mechanism exists.

\subsection{Knee Morphometry}

\subsubsection{Tibial Slopes}

The results of studies measuring the medial and lateral tibial slopes in the general population are varied and often depend on the measurement techniques used. The mean values found in X-ray studies ranging from $8.5^{\circ}$ to $10^{\circ}$. In MRIbased studies, the medial and lateral slopes have means ranging from $-2.9^{\circ}$ to $10.7^{\circ}$ and $-1.8^{\circ}$ to $7.52^{\circ}$ respectively [1].

In our study we obtained means of $4.65^{\circ}$ and $3.37^{\circ}$ for the medial and lateral slopes respectively in the two groups. There was no statistically significant difference in measurements of tibial slopes between males and females in each of the study groups. There was a statistically significant difference for the lateral slopes between the case and the control group, with p-value estimated at 0.039 
from the student test $(\mathrm{p}<0.05)$.

Hashemi et al reported higher medial and lateral tibial slopes in patients with ACL ruptures compared with a group without ACL rupture [12] [13]. Several other studies, such as Khan et al., Stijak L et al., Bisson LJ et al., Simon RA et al., found this difference only for the lateral slope [4] [14] [15]. Stijak et al found a median slope higher than the lateral slope in subjects without ACL rupture, a finding similar to what we obtained in our study [15]. We believe that these differences between the studies would be related to the different techniques used in the angle measurement.

The combined method we used, with precise selections of sagittal slices, brings us closer to the results obtained by Khan et al. who used the same method [1]. The hypothesis that there is a relationship between lateral tibial slope and ACL ruptures is accurate in our sample. On the other hand, we found no relationship between ACL ruptures and medial slope.These findings are consistent with several studies notably those who used similar measurement methods.

\subsubsection{Intercondylar Notch Index}

Index of the intercondylar notch: We found no statistically significant difference for the intercondylar notch index between the case and control groups. These indices also show no difference with respect to the patient. Tomas Fernandez-Jaen et al found a statistically significant difference using the measurement of the width of the intercondylar notch [9].

Other authors have described that a small intercondylar notch exposes patients to ACL ruptures, including Freychet et al. [6], who found a statistically lower intercondylar notch index in the case group at 0.244 against 0.263 in the control group. Similar results were obtained by Fernandez-Jaen et al. [9]. These contradictory results could be due to the choice of the evaluation parameter of the intercondylar notch (between the index, the size or surface of the notch) and the measurement technique. Studies that used the size or surface area of the intercondylar notch had the most statistically significant differences between patients with and without ACL rupture. This was notably observed in studies conducted by Tomas Fernandez-Jaen [9] et al. and Freychet et al. [6].

\section{Conclusions}

Partial ACL ruptures were most frequent (53\%) in our study, and were characterized by morphological and signal abnormalities of the ligament as the primary direct sign. The most frequent associated signs were mirror-image bone contusions, intra-articular effusion and lesions of the medial meniscus.

This study showed that patients with ACL rupture had a statistically higher lateral tibial slope than those without ACL rupture. On the other hand, there is no difference between the two groups concerning the intercondylar notch index and the medial tibial slope. Assessment of the lateral tibial slope could be used in the medical follow-up of athletes, patients with a history of ACL rupture and in the surgical management of patients with ACL ruptures. 
We therefore recommend in studies in the future, exploring others risk factors of ACL rupture.

\section{Conflict of Interest}

The authors declare that they have no conflict of interest.

\section{References}

[1] Mohammad, S.K., Jong, K.S. and Eun, K.S. (2011) Risk Factors for Anterior Cruciate Ligament Injury: Assessment of Tibial Plateau Anatomic Variables on Conventional MRI Using a New Combined Method. International Orthopaedics, 35, 1251-1256. https://doi.org/10.1007/s00264-011-1217-7

[2] Tapouh, J.R.M., Moifo, B., Zoe, C.M., Guifo, M.L., Tebere, H., Edzimbi, A.L. and Amvene, S.N. (2015) Potential Association between Anterior Cruciate Ligament Tear and "Bi-Collateral" Ligamentous Rupture: A Retrospective Study. Open Journal of Radiology, 5, 217-223. https://doi.org/10.4236/ojrad.2015.54030

[3] Myer, G.D., Heidt, R.S., Waits, C., Finck, S., Stanfield, D., Posthumus, M. and Hewett, T.E. (2014) Sex Comparison of Familial Predisposition to Anterior Cruciate Ligament Injury. Knee Surgery, Sports Traumatology, Arthroscopy, 22, 387-391. https://doi.org/10.1007/s00167-013-2822-3

[4] Simon, R.A., Everhart, J., Nagaraja, H.N. and Chaudhari, A.M. (2010) A Case-Control Study of Anterior Cruciate Ligament Volume, Tibial Plateau Slopes and Intercondylar Notch Dimensions in ACL Injured Knees. Journal of Biomechanics, 43, 1702-1707. https://doi.org/10.1016/j.jbiomech.2010.02.033

[5] Wordeman, S.C., Quatman, C.E., Kaeding, C.C. and Hewett, T.E. (2012) In Vivo Evidence for Tibial Plateau Slope as a Risk Factor for Anterior Cruciate Ligament Injury. The American Journal of Sports Medicine, 40, 1673-1681. https://doi.org/10.1177/0363546512442307

[6] Freyche, B., Fournier, J., Bergeraul, F., Courtivron, B. and Bonnard, C. (2014) Facteurs de risque anatomiques des ruptures du LCA chez l'enfant: Etude castémoin radiologique descriptive de l'échancrure inter-condylienne. Revue de Chirurgie Orthopédique et Traumatologique, 100, 246-249.

https://doi.org/10.1016/j.rcot.2014.09.088

[7] Sonnery-Cottet, B., et al. (2014) Influence de la pente tibiale et de l'échancrure intercondylienne dans la rupture du ligament croisé antérieur. Journal de Traumatologie du Sport, 31, 54-57. https://doi.org/10.1016/j.jts.2013.12.004

[8] Smith, H.C., Vacek, P., Johnson, R.J., Slauterbeck, J.R., Hashemi, J., Shultz, S., et al. (2012) Risk Factors for Anterior Cruciate Ligament Injury. Sports Health, 4, 69-78. https://doi.org/10.1177/1941738111428281

[9] Fernandez-Jaen, T., Lopez-Alcorocho, J.M., Rodriguez-Inigo, E. and Castellan, F. (2015) The Importance of the Intercondylar Notch in Anterior Cruciate Ligament Tears. Orthopaedic Journal of Sports Medicine, 3, 64-70. https://doi.org/10.1177/2325967115597882

[10] Donell, S.T., Marshall, T.J., Darrah, C. and Shepstone, L. (2006) Cruciate Ligament Assessment in MRI Scans: A Pilot Study of a Static Drawer Technique. Knee, 13, 137-144. https://doi.org/10.1016/j.knee.2005.12.004

[11] Guenoun, D., Le Corroler, T., Amous, Z., Pauly, V., Sbihi, A. and Champsaur, P. (2012) Apport de l'IRM dans le diagnostic des ruptures traumatiques du ligament croisé antérieur. Journal de Radiologie Diagnostique et Interventionnelle, 93, 357-367. 
https://doi.org/10.1016/j.jradio.2011.02.030

[12] Hashemi, J., Chandrashekar, N. and Gill, B. (2008) The Geometry of the Tibial Plateau and Its Influence on the Biomechanics of the Tibiofemoral Joint. The Journal of Bone and Joint Surgery. American Volume, 90, 2724-2734.

https://doi.org/10.2106/JBJS.G.01358

[13] Hashemi, J., Chandrashekar, N., Mansouri, H., Gill, B., Slauterbeck, J.R., Schutt, R.C., Dabezies, E. and Beynnon, B.D. (2010) Shallow Medial Tibial Plateau and Steep Medial and Lateral Tibial Slopes: New Risk Factors for Anterior Cruciate Ligament Injuries. The American Journal of Sports Medicine, 38, 54-62. https://doi.org/10.1177/0363546509349055

[14] Stijak, L., Herzog, R.F. and Schai, P. (2008) Is There an Influence of the Tibial Slope of the Lateral Condyle on the ACL Lesion? A Case-Control Study. Knee Surgery, Sports Traumatology, Arthroscopy, 16, 112-117.

https://doi.org/10.1007/s00167-007-0438-1

[15] Bisson, L.J. and Gurske-De Perio, J. (2010) Axial and Sagittal Knee Geometry as a Risk Factor for Non Contact Anterior Cruciate Ligament Tear: A Case-Control Study. Arthroscopy, 26, 901-906. https://doi.org/10.1016/j.arthro.2009.12.012 